\title{
Two new contingent aftereffects: Perceived auditory duration contingent on pitch and on temporal order
}

\author{
JAMES T. WALKER and ARTHUR L. IRION \\ University of Missouri-St. Louis, St. Louis, Missouri 63121
}

\begin{abstract}
If a low-pitched tone of long duration alternates with a high-pitched short tone during an inspection period of a few minutes, then a high test tone of intermediate length sounds longer than a low test tone of equal length. Thus, a contingent aftereffect occurs, wherein the perceived duration of a test tone is contingent-dependent-on its pitch. A second contingent aftereffect occurs if pairs of tones of the same pitch, the first short and the second long, are presented repeatedly during an inspection period. If a pair of test tones of equal and intermediate length is then presented, the first tone sounds longer than the second.
\end{abstract}

This paper reports two new contingent aftereffects of perceived auditory duration. Heretofore, no contingent aftereffect has been demonstrated in the domain of time perception. The first aftereffect is pitch contingent. After listening to a series of lowpitched tones of long duration $(600 \mathrm{~Hz}, 600 \mathrm{msec})$ alternating with high short tones $(900 \mathrm{~Hz}, 200 \mathrm{msec})$ during an inspection period of a few minutes, a high test tone of intermediate length $(400 \mathrm{msec})$ sounds longer than a low test tone of equal length. An inspection series of low-short and high-long tones produces an opposite aftereffect: A low test tone sounds longer than a high tone of equal length. Thus, the perceived duration of a test tone is contingentdependent-on the pitch of the tone and on the prior relationship between the length and pitch of the inspection tones.

In the second new aftereffect, a pair of short and long tones (200 and $1,000 \mathrm{msec})$ of the same pitch $(600 \mathrm{~Hz})$ is presented repeatedly during an inspection period. Tone pairs are separated by silent intervals of $1.4 \mathrm{sec}$. When a pair of $600-\mathrm{Hz}$ test tones of equal and intermediate length $(400 \mathrm{msec})$ is then presented, the first test tone sounds longer than the second. Thus, the perceived duration of a test tone is contingent on its temporal order within a test pair and on the prior relationship between length and temporal order within inspection pairs.

The classic example of a contingent aftereffect, the McCollough effect, occurs in the visual modality (McCollough, 1965). After alternately viewing a horizontal grating of red and black lines and a vertical grating of green and black, a horizontal achromatic

A version of this article was presented at the annual meeting of the Psychonomic Society, San Antonio, Texas, November 1978. Requests for reprints should be sent to James T. Walker, Department of Psychology, University of Missouri-St. Louis, St. Louis, Missouri 63121. test grating looks greenish and a vertical achromatic grating looks reddish. Thus, two opposite complementary color aftereffects occur in the same region of the visual system. In that respect, the McCollough effect differs markedly from conventional afterimages and other simple aftereffects, where only a single aftereffect occurs in a particular region of a sensory system (Mayhew \& Anstis, 1972).

A simple aftereffect of perceived duration has been demonstrated previously in the auditory modality. An inspection tone of $4 \mathrm{sec}$ preceding a 2 -sec test tone shortens the perceived duration of the test tone, as measured by a reproduction method (Huppert \& Singer, 1967). A simple aftereffect of perceived pitch has also been demonstrated previously. If an inspection tone of $800 \mathrm{~Hz}$ is presented to one ear for $2 \mathrm{~min}$, then a test tone of $500 \mathrm{~Hz}$ sounds lower to that ear than a tone of the same frequency presented to the other ear, and a test tone of $1,200 \mathrm{~Hz}$ sounds higher (Békésy, 1960).

Numerous contingent aftereffects occur in the visual modality involving such sensory dimensions as color, orientation, visual texture, and motion (for example, Favreau, Emerson, \& Corballis, 1972; Held \& Shattuck, 1971; Hepler, 1968; Leppmann, 1973; Skowbo, Timney, Gentry, \& Morant, 1975; Walker, 1972). A few contingent aftereffects have been demonstrated in the tactual-kinesthetic modality involving the dimensions of length, width, and orientation (Walker, 1977, 1978; Walker \& Shea, 1974). In every contingent aftereffect, during the inspection period, two levels on one sensory dimension are paired with two levels on another; subsequently, the perceived location of a test stimulus on one sensory dimension is contingent on its location on the other. Thus, the present auditory aftereffects are closely analogous to other contingent aftereffects in other modalities.

In the present study, pitch-contingent and order- 
contingent aftereffects of perceived duration were measured by a method of magnitude estimation. The measurement procedures here closely parallel the magnitude-estimation procedures used in earlier studies of contingent aftereffects (for example, Walker, 1978).

\section{EXPERIMENT 1: PITCH-CONTINGENT AFTEREFFECTS}

This experiment was designed to measure the aftereffects produced by two inspection conditions: (1) low-long and high-short inspection tones, and (2) high-long and low-short inspection tones.

\section{Method}

Subjects. Twenty-four men, undergraduate psychology students at the University of Missouri-St. Louis, served as subjects; some were volunteers, and some participated to fulfill a course requirement. Four potential subjects were replaced for the reasons described in the procedures section.

Apparatus. The tones were essentially sine waves of 600 and $900 \mathrm{~Hz}$, a musical fifth apart, presented at $80 \mathrm{~dB}$ SPL through a speaker in a soundproof chamber. All tones and experimental instructions were presented by tape recorder. The $600-$ and $900-\mathrm{Hz}$ tones will be designated, respectively, as low (L) and high (H). The test tones were the following three pairs of high and low tones, with durations indicated in milliseconds: L600-H400, L400$\mathrm{H} 400$, and $\mathrm{L} 400-\mathrm{H} 600$. The following tones were used under the two inspection conditions, with durations in milliseconds: L600$\mathrm{H} 200$ and $\mathrm{L} 200-\mathrm{H} 600$. The time intervals used here are within the range where the Weber ratio is minimal, and are also close to the interval of indifference, that time interval which is neither under- nor overestimated (Fraisse, 1963; Woodrow, 1951).

Procedure. For control purposes, pretest measurements were made before the inspection period. Each subject made four practice judgments without any feedback, and then judged the three pairs of high and low test tones (L600-H400, L400-H400, and L400-H600). The three pairs were presented in all six possible sequences, each sequence being used for four subjects. For a single pretest measure, each pair of tones was presented three times, with silent intervals of $400 \mathrm{msec}$ between the tones within a pair and also between pairs of tones. The experimenter asked whether the low or the high tone sounded longer, and then asked how much longer that tone sounded in percentage terms. Judgments of equality were permitted. Similar magnitude-estimation procedures have been used in other studies of contingent aftereffects (Walker, 1977, 1978; Walker \& Shea, 1974). The subject was given $10 \mathrm{sec}$ in which to judge the test tones. Two potential subjects were replaced because of their inability to make the required judgments. Any subject was replaced who said that any test tone sounded more than $100 \%$ longer than another. Since the largest objective difference within a pair of test tones was $50 \%$, extreme judgments were eliminated in the interest of reducing error variance. Two potential subjects were replaced for that reason.

A 3-min inspection period followed the pretest measurements. For half the subjects, the inspection tones were $\mathrm{L} 600-\mathrm{H} 200$, and for the other half $\mathrm{L} 200-\mathrm{H} 600$ (durations in milliseconds). The starting tones of the inspection periods, low first or high first, were counterbalanced across those two conditions. All inspection tones were separated by silent intervals of $400 \mathrm{msec}$. After the inspection period, three posttest measurements were made using the same pairs of test tones and the same procedures as in the pretest measurements, except that a different sequence of test pairs was used. For a given subject, the same starting tone-high or low-was used throughout the pretest measures, the inspection tones, and the posttest measures. All posttest measurements were retained without regard to magnitude. Two subjects made posttest judgments indicating that one test tone sounded more than $100 \%$ longer than another.

\section{Results}

Pretest measures. For each pair of test tones, the objective comparison is the percentage by which the longer tone exceeds the shorter, a negative sign indicating that the low tone is longer. Thus, the objective comparisons for the above test pairs are $-50 \%, 0 \%$, and $50 \%$. The subjective comparison is the percentage by which the subject estimated the longer sounding tone to exceed the shorter sounding, a negative sign indicating that the low tone sounded longer.

The pretest measures (Figure 1A) show a strong relationship between subjective and objective comparisons of the test tones, the linear trend accounting for $77.57 \%$ of the within-subjects variance $[F(1,46)$ $=159.14, \mathrm{p}<.001]$. Those results validate the measurement procedure, to the extent that subjective comparisons are an increasing linear function of objective comparisons.

Aftereffect measures. Using the pretest measures, an individual linear regression equation was found for each subject expressing subjective comparison as a function of objective comparison. Each subject's aftereffect scores were found by algebraically subtracting predicted subjective comparisons from posttest measures. The L600-H200 inspection condition produced a significant aftereffect with a positive sign, while the $\mathrm{L} 200-\mathrm{H} 600$ condition produced a significant aftereffect with a negative sign, as expected (Table 1). In a sense, both conditions produced "negative" aftereffects, since the first inspection condition made a low test tone sound shorter and the second made a low tone sound longer. In this respect, the present aftereffect is consistent with other contingent and most simple aftereffects.

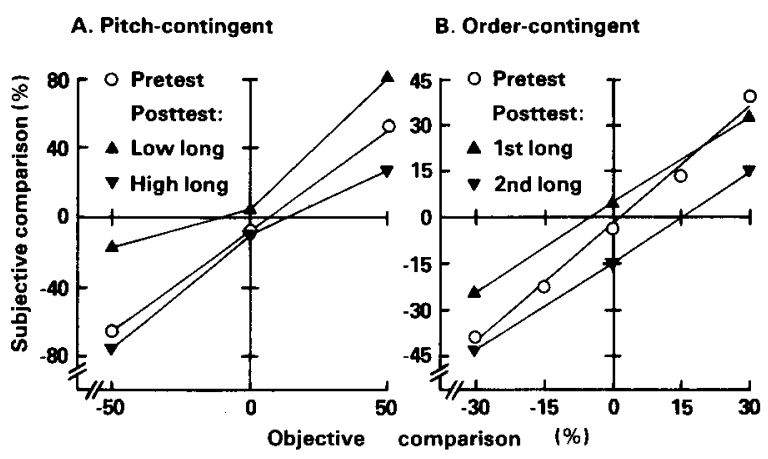

Figure 1. Mean pretest and posttest measures. Least-squares regression lines fitted to pretest measures. Different posttest symbols indicate measures following different inspection conditions: In (A), low-long (L600-H200) and high-long (L200-H600); in (B), 1st-long (1,000-200) and 2nd-long (200-1,000). 
Table 1

Mean Aftereffects and Standard Deviations (in Percent)

\begin{tabular}{|c|c|c|c|c|c|}
\hline \multirow{2}{*}{$\begin{array}{l}\text { Inspection } \\
\text { Condition }\end{array}$} & & \multicolumn{4}{|c|}{$\begin{array}{c}\text { Objective Comparison } \\
\text { of Test Tones }\end{array}$} \\
\hline & & $-50 \%$ & $0 \%$ & $50 \%$ & Combined \\
\hline \multicolumn{6}{|c|}{ Experiment 1: Pitch-contingent Aftereffect $(\mathrm{N}=24)$} \\
\hline $\mathrm{L} 600-\mathrm{H} 200^{\mathrm{a}}$ & $\begin{array}{l}\mathbf{M} \\
\mathrm{SD}\end{array}$ & $\begin{array}{l}55.18 * * \\
57.26\end{array}$ & $\begin{array}{l}11.77 \\
29.90\end{array}$ & $\begin{array}{l}22.93 \\
47.28\end{array}$ & $\begin{array}{l}29.96 * * \\
28.51\end{array}$ \\
\hline \multirow[t]{2}{*}{ L200-H600 } & $\mathbf{M}$ & -16.76 & -2.22 & -16.68 & $-11.88^{*}$ \\
\hline & SD & 41.72 & 19.55 & 41.93 & 17.24 \\
\hline \multirow[t]{2}{*}{ Combinedb } & $\mathbf{M}$ & $35.97 * *$ & * 6.99 & $19.80^{*}$ & $20.92 * * *$ \\
\hline & SD & 52.78 & 25.18 & 43.82 & 24.82 \\
\hline \multicolumn{6}{|c|}{ Experiment 2: Order-contingent Aftereffect $(N=24)$} \\
\hline \multirow[t]{2}{*}{$1,000-200^{\mathrm{a}}$} & $\mathbf{M}$ & $18.17^{*}$ & 7.70 & -4.43 & 7.14 \\
\hline & SD & 24.32 & 18.41 & 25.05 & 16.10 \\
\hline \multirow[t]{2}{*}{$200-1,000$} & $\mathrm{M}$ & -3.62 & $-13.05^{*}$ & -19.98 & $-12.22^{*}$ \\
\hline & SD & 32.45 & 17.32 & 39.60 & 18.20 \\
\hline \multirow[t]{2}{*}{ Combined $\mathbf{b}$} & $\mathbf{M}$ & 10.89 & $10.38 *$ & 7.78 & $9.68 *$ \\
\hline & $\mathrm{SD}$ & 29.01 & 17.69 & 34.72 & 17.01 \\
\hline
\end{tabular}

aDurations of inspections are in milliseconds. bFor combined inspection conditions, aftereffects in the expected directions were given positive signs. ${ }^{*} p<.05 ;{ }^{* *} p<.01 ;{ }^{* * *} p<.001$.

The aftereffect scores were subjected to a 2 by 2 by 3 analysis of variance where the other factors were inspection condition (L600-H200, L200-H600), starting tone (long, short), and objective comparison of test pair $(-50 \%, 0 \%, 50 \%)$, with repeated measures on the last factor. Only the effect of inspection condition was significant $[\mathrm{F}(1,20)=18.49, \mathrm{p}<.01]$. The L600-H200 inspection condition produced a numerically greater aftereffect than the $\mathrm{L} 200-\mathrm{H} 600$ condition (Table 1), but the aftereffects do not differ significantly in magnitude $[\mathrm{t}(22)=1.88, \mathrm{p}<.10]$.

\section{EXPERIMENT 2: ORDER-CONTINGENT AFTEREFFECTS}

This experiment was designed to measure the aftereffects produced by two inspection conditions, shortlong and long-short pairs of inspection tones of the same frequency.

\section{Method}

Subjects. Twenty-four men, undergraduate psychology students at the University of Richmond, participated as a course requirement.

Apparatus. The tones and experimental instructions were presented in a quiet room through the speaker of a tape recorder. All tones were of the same frequency, $600 \mathrm{~Hz}$, and were presented at about $70 \mathrm{~dB}$ SPL.

Procedure. Pretest measurements were made using the following five pairs of tones, with durations in milliseconds: $520-400,460-$ $400,400-400,400-460$, and $400-520$. There was a silent interval of $400 \mathrm{msec}$ between the members of each pair of tones. All five pairs of tones were presented to each subject in a random sequence. Six different random sequences were used, with four subjects assigned to each sequence. For each pretest measure, a pair of tones was presented only once, and the subject was given $10 \mathrm{sec}$ in which to respond. The subject indicated whether the first or second tone sounded longer, and then judged the relative durations of the tones in percentage terms. Judgments of equality were not allowed. Five practice trials were given without any feedback to the subject. For the practice trials, the sequence of the five tone pairs was the mirror image of the sequence used for the pretest measures. It was unnecessary to replace any subject because of an extreme judgment, using the same criteria as in Experiment 1.

Each subject was given three 90 -sec inspection periods, each followed by a single presentation of a pair of test tones. Half the subjects were assigned to each of two inspection conditions, short-long (200-1,000 msec) and long-short (1,000-200 msec). A silent interval of $\mathbf{4 0 0} \mathrm{msec}$ occurred within each pair of inspection tones, and there was a silent interval of $1.4 \mathrm{sec}$ between pairs. Posttest measures used the following three pairs of tones: $520-400$, $400-400$, and $400-520$. The sequence of test pairs was determined for each subject by a row of a 3 by 3 Latin square.

\section{Results}

Pretest measures. In this experiment, the objective comparison has a negative sign when the first tone exceeds the second, and thus the objective comparisons for the above test pairs are $-30 \%,-15 \%$, $0 \%, 15 \%$, and $30 \%$. The linear trend in the pretest measures relating subjective and objective comparisons (Figure 1B) accounts for $69.39 \%$ of the withinsubjects variance $[F(1,92)=212.18, p<.001]$, and there is no significant deviation from that linear trend $[F(3,92)=.53]$.

Aftereffect measures. Aftereffect scores were found using the regression method described in the first experiment. A repeated-measures Latin squares analysis of variance (Winer, 1971, plan 8, p. 723) showed only significant effects of inspection condition $[F(1,18)=8.64, p<.01]$ and objective comparison of test pairs $[\mathrm{F}(2,44)=3.43, \mathrm{p}<.05]$. Across the three test measures, the 200-1,000 inspection condition produced a significant aftereffect (Table 1), but the 1,000-200 condition did not. Both aftereffects are in the expected direction, and do not differ significantly in magnitude $[t(22)=.72]$. The magnitude of the combined aftereffect for both inspection conditions $(9.68 \%)$ differs significantly from zero $[t(23)=2.79, p<.02]$.

\section{GENERAL DISCUSSION}

In terms of the operations used to produce the present aftereffects of temporal duration, these phenomena appear quite analogous to the McCollough effect and other contingent aftereffects. Two kinds of models, one based on neural adaptation and the other based on classical conditioning, have been proposed to account for contingent aftereffects. Those models will be described and then applied to the present contingent aftereffects.

McCollough (1965) suggested that the adaptation of color-coded orientation-specific edge detectors might explain her aftereffect, and, indeed, a few such detectors were later found in the visual cortex of the monkey (Hubel \& Wiesel, 1968). Extending that 
model to the present pitch-contingent aftereffect, suppose there are duration detectors in the auditory system, each maximally sensitive to a specific duration but also responsive to a range of durations. Further, suppose that some of those duration detectors are also pitched-coded, that is, sensitive to the pitch of a tone as well as to its duration. Adapting a set of such double-duty detectors to a low tone of long duration would produce a negative aftereffect in the perceived duration of a low test tone of intermediate length. Similar mechanisms have been proposed to account for simple aftereffects (Osgood \& Heyer, 1952; Sekuler \& Pantle, 1967) and have been extended to other contingent aftereffects as well (Skowbo et al., 1975; Walker, 1977). If there are auditory duration detectors that are also sensitive to the temporal order of tones in a sequence, then the preceding model can be extended to account for the order-contingent aftereffect of perceived duration.

Several workers have criticized the neuraladaptation model of contingent aftereffects, and some have offered explanations based on classical conditioning (Harris \& Gibson, 1968; Jones \& Holding, 1975; Murch, 1972, 1976). In a classical conditioning model of the McCollough effect, orientation can be considered a conditioned stimulus and color an unconditioned stimulus. After pairing the horizontal orientation with the color red, for example, a traditional interpretation of classical conditioning would predict a red aftereffect in a horizontal achromatic test grating-but such a grating elicits a green aftereffect, essentially the complement of the red unconditioned stimulus (Walker, 1977). Proponents of the conditioning model argue that the unconditioned response to a red stimulus is the fatigue of a red process, but surely another unconditioned response to that stimulus is the perception of red. It is unclear why the former response, rather than the latter, comes to be attached to the conditioned stimulus.

Extending the classical-conditioning model to the present pitch-contingent aftereffect, pitch can be considered a conditioned stimulus and duration an unconditioned stimulus. Pairing a low pitch with a long duration and a high pitch with a short duration should make a low-pitched test tone of intermediate duration sound longer-but such a test tone sounded shorter instead. An analogous difficulty arises when the classical-conditioning model is extended to the present order-contingent aftereffect.

The present contingent aftereffects-and indeed, contingent aftereffects in general-pose logical difficulties for the classical conditioning model, since the responses that come to be associated with the test stimuli are opposite to the responses expected through traditional classical conditioning. Although the neural adaptation model circumvents those logical difficulties, there is no neurophysiological evidence of the kinds of duration-detection mechanisms that such a model requires. In the absence of such evidence, attribution of the present contingent aftereffects to a neural-adaptation model is highly speculative.

\section{REFERENCES}

BÉ KÉsY, G. von. Experiments in hearing. New York: McGrawHill, 1960.

Favreau, O. E., Emerson, V. F., \& Corballis, M. C. Motion perception: A color-contingent aftereffect. Science, 1972, 176, 78-79.

Fraisse, P. [The psychology of time] (J. Leith, trans.). New York: Harper \& Row, 1963. (Originally published, 1963)

Harris, C. S., \& Gibson, A. R. Is orientation-specific color adaptation in human vision due to edge detectors, afterimages, or "dipoles"? Science, 1968, 162, 1506-1507.

Held, R., \& Shattuck, S. Color- and edge-sensitive channels in the human visual system: Tuning for orientation. Science, $1971,174,314-316$.

Hepler, N. Color: A motion-contingent aftereffect. Science, 1968, 162, 376-377.

Hubel, D. H., \& Wiesel, T. N. Receptive fields and functional architecture of monkey striate cortex. Journal of Physiology, $1968,195,215-243$.

Huppert, F., \& Singer, G. An aftereffect in judgment of auditory duration. Perception \& Psychophysics, 1967, 2, 544-546.

Jones, P. D., \& Holding, D. H. Extremely long-term persistence of the McCollough effect. Journal of Experimental Psychology: Human Perception and Performance, 1975, 1, 323-327.

LePPMANN, P. K. Spatial frequency dependent chromatic aftereffects. Nature, 1973, 242, 411-412.

Mayhew, J. E. W., \& Anstis, S. M. Movement aftereffects contingent on color, intensity, and pattern. Perception \& Psychophysics, 1972, 12, 77-85.

McCollough, C. Color adaptation of edge-detectors in the human visual system. Science, 1965, 149, 1115-1116.

Murch, G. M. Binocular relationships in a size and color orientation specific aftereffect. Journal of Experimental Psychology, $1972,93,30-34$.

Murch, G. M. Classical conditioning of the McCollough effect: Temporal parameters. Vision Research, 1976, 16, 615-619.

OSGOOD, C. E., \& HEYER, A. W. A new interpretation of figural aftereffects. Psychological Review, 1952, 59, 98-118.

Sekuler, R., \& Pantle, A. A model for aftereffects of seen movement. Vision Research, 1967, 7, 427-439.

Skowbo, D., Timney, B. N., Gentry, T. A., \& Morant, R. B. McCollough effects: Experimental findings and theoretical accounts. Psychological Bulletin, 1975, 82, 497-510.

WALKER, J. T. A texture-contingent visual motion aftereffect. Psychonomic Science, 1972, 28, 333-335.

WALKER, J. T. Orientation-contingent tactual size aftereffects. Perception \& Psychophysics, 1977, 22, 563-570.

WALKER, J. T. Simple and contingent aftereffects in the kinesthetic perception of length. Journal of Experimental Psychology: Human Perception and Performance, 1978, 4, 294-301.

Walker, J. T., \& SheA, K. S. A tactual size aftereffect contingent on hand position. Journal of Experimental Psychology, 1974, 103, 668-674.

WINER, B. J. Statistical principles in experimental design (2nd ed.). New York: McGraw-Hill, 1971.

Woodrow, H. Time perception. In S. S. Stevens (Ed.), Handbook of experimental psychology. New York: Wiley, 1951.

(Received for publication February 5, 1979; accepted June 29, 1979.) 